\title{
Research on the Innovation of Vocal Teaching Course Based on Multicultural Perspective
}

\author{
Dou Lianxiu \\ Dongchang College of Liaocheng University, Shandong, China, 252000
}

Keywords: multiculturalism; national vocal music; innovative teaching; curriculum optimization

Abstract: With the development of economic globalization, the exchanges and integration of cultures around the world have shown a diversified development trend. The national vocal music driven by multiculturalism presents many new features. In order to practice students' sensitivity to music, music teachers need to constantly urge students to practice. The same songs are different in different styles of singing, so students should strengthen their understanding of music and appreciate different music. In the contemporary era, vocal education workers have the responsibility and obligation to inherit and carry forward the national vocal music.

\section{Introduction}

With the development of the economy and the improvement of people's living standards, people have put forward higher requirements for the improvement of spiritual civilization. In the practice of vocal practice, teachers should strive to guide students to establish a correct awareness of vocal music and respect the traditional vocal culture of our country. In addition, it is necessary to recognize the importance of local culture teaching, fully integrate the characteristics of national culture into the curriculum of students, and enhance the local vocal culture of students. Under the background of multiculturalism, the development of vocal music education in colleges and universities in China not only has a good development environment, but also encountered many problems ${ }^{[1]}$.

\section{The development status of national vocal music education}

\subsection{Teaching mode is backward}

In China's traditional national vocal music education mode, most of them are learning Western music teaching mode, not only in the curriculum of music teaching but also in the music singing method. As shown in Figure 1 below, it is the current status of the framework of vocal music teaching in China:

Under the learning of this model as shown in Figure 1, although the students have mastered the basic music knowledge and singing method, they have problems in learning the national music of our country. The students will not be able to re-learn the national music because of the previous 
learning methods. It slows down the progress of students learning ethnic music, and also causes students to have a single style of music ${ }^{[2]}$.

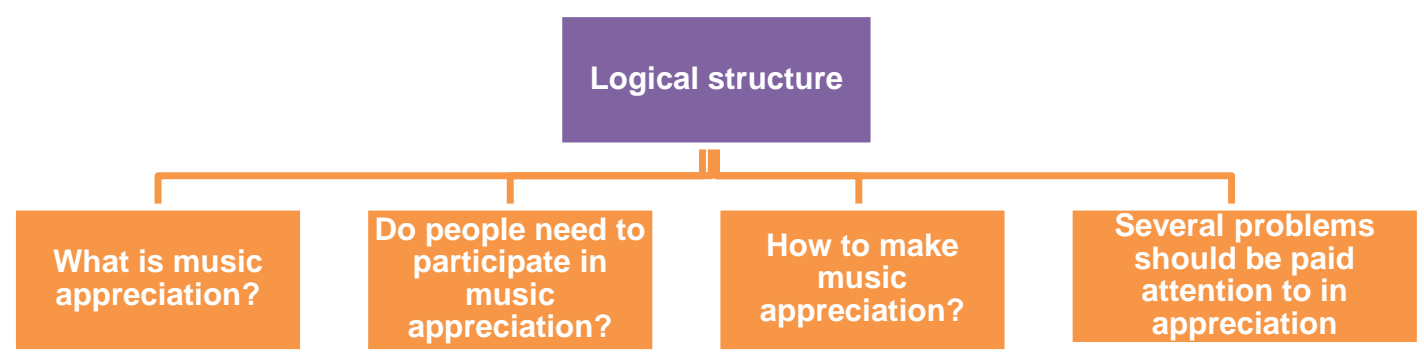

Figure 1 The basic framework of the traditional national vocal music teaching curriculum ${ }^{[1]}$

\subsection{There is no systematic teaching system}

China's national vocal music teaching knowledge simply borrows or plagiarizes Western singing practice patterns, does not form its own teaching system, and also focuses on learning from the West in the setting of vocal music teaching courses. This leads to our national music teaching system not in line with the development of national music teaching in colleges and universities, followed by the lack of awareness and opportunities to learn from folk singers, operas and trousers. Therefore, the original national style and characteristics of students are difficult to preserve.

\subsection{Ignoring the development of the characteristics of democratic vocal music}

China's traditional teaching mode is to carry out unified training. No matter what kind of music styles are practiced together, this restricts the development of the characteristics of Chinese national music. At the same time, it does not highlight the characteristics of Chinese national music and the singing of national singers. China is a multi-ethnic country. Every nation has its own national music. Therefore, the music style and singing method are also different. But now the national vocal music education is a unified singing practice for students and unified training, which leads to different nationalities. The songs tend to be similar in singing and style, which hinders the development of the diversity of Chinese national vocal music ${ }^{[3]}$.

\section{How to promote the development of national vocal music teaching from the perspective of multiculturalism}

\subsection{Introducing advanced teaching mode}

The current situation of "one thousand people singing" in the national vocal music education in China is mainly due to the fact that it is too dependent on the teaching mode of the West and does not conform to the mode of development of its own national vocal music. Therefore, major universities should introduce advanced teaching models, not only to learn unified vocal theory knowledge, but also to strengthen students' learning of different ethnic music. Students' learning of the characteristics of different ethnic music should dominate the whole vocal learning. In this way, we can give full play to the traditional characteristics of Chinese national vocal music and promote our national culture. As shown in Figure 2 below, it is a distinct new mode of vocal music teaching:

The teaching of vocal music in the multicultural perspective described in Figure 2 above can be applied to teaching practice. For example, how to vocalize the vocal course setting, how to sing the treble, the bass, how to use your own breath, etc., these can allow students to practice together, 
because no matter what songs are sung, these are the most basic. Then, according to different ethnic groups, vocal music can be divided into classes, such as Hue, Mongolian, and Yi, and they can also learn to arrange together in a similar way ${ }^{[3]}$.

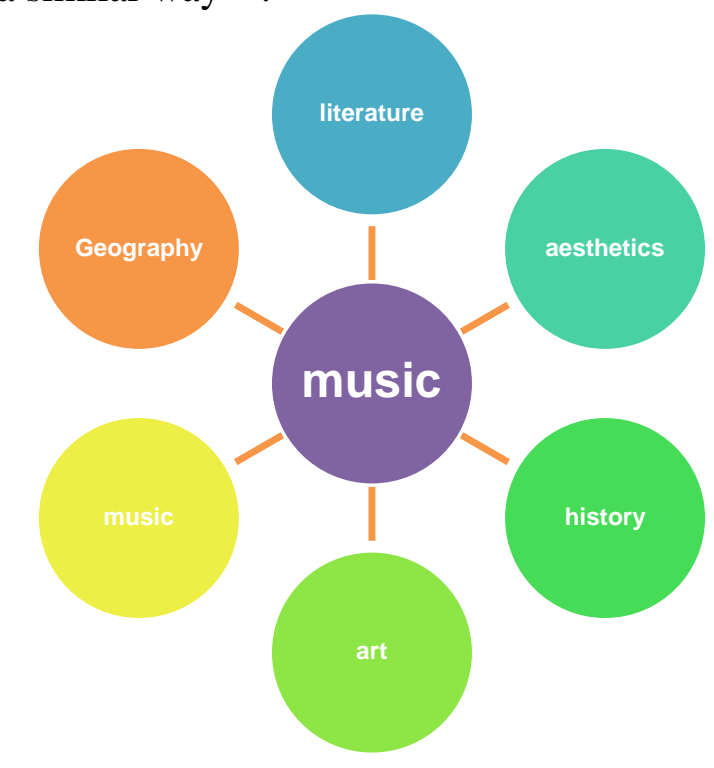

Figure 2 Vocal teaching mode from the perspective of multiculturalism ${ }^{[3]}$

\subsection{Establish a sound teaching system}

There are 56 ethnic groups in China, each of which has its own national music culture and national music style. Each ethnic group also has its own excellent singer. Therefore, schools should be based on the multi-ethnic culture of our country, and teach differently according to different national characteristics and styles, as well as different students' expressions of national music. For example, in the course of setting up the course, in addition to the basic knowledge of vocal music, everyone should study together. In the study of music of various nationalities, it is necessary to carry out class work. Mongolian, Xinjiang, Hue, Han and other ethnic music should be studied differently.

\subsection{Focus on the development of the characteristics of national vocal music}

National vocal music education should be combined with national culture and pay attention to the development of national vocal music. Therefore, in national vocal music education, national vocal music can be combined with national culture and customs, and national music can be created on the basis of national culture and background. For example, Mongolia has a vast territory and Mongolians are warm and hospitable. Therefore, most of Mongolia's music has a vast, bold and rough grassland ethnic characteristic, as shown in the following section:

$1=\mathrm{D} 2 / 4$

$$
5 \underline{35}|35| 1 \cdot \underline{6}|5-| \underline{55} 61|3 \underset{2}{3}| 1-\mid 1-\|
$$

The treble of the treble is generally open or closed, the middle of the sound is more flexible, and the lining at the end the word is usually a semi-opening or closed accent. Teenager's "Paradise" has a very distinctive Mongolian national character. Even if it is a person who has never heard of this song, as long as the melody of music comes out, everyone knows that it is a Mongolian song ${ }^{[4]}$. 


\section{Reform and innovation of vocal music teaching curriculum based on multicultural vision}

\subsection{Promoting the educational foundation of the national singing art}

In order to ensure the effective development of vocal music multicultural education in colleges and universities in China, we must pay attention to the basic role of national singing art in college vocal music education. From a macroscopic perspective, when developing national vocal music education, colleges and universities need to continuously explore and study the main laws of the practice of national singing art in accordance with the norms of naturalistic education, and on the basis of practical laws. Innovatively improve the practice model of vocal music education. In the process of vocal music multicultural education innovation, it absorbs the essence of different singing styles of different nationalities and regions, and organizes the commonality, regular knowledge and skills. This will not only enhance the richness and diversity of China's national singing art, but also promote the diversified development of China's national singing art, and it will further enhance the local vocal music education in China.

\subsection{Create a multi-cultural education curriculum system for college vocal music}

First of all, we must fully understand the diversified development trend of vocal music in China, and seek the balance point of vocal music multicultural education according to the actual teaching situation of the school. Only by combining music teaching courses with multicultural education can we ensure that colleges and universities in vocal music education ensure that students have the opportunity to contact music of different nationalities and regions. Secondly, when developing vocal music education, colleges and universities should innovate vocal education methods and fully mobilize the initiative and creativity of students. Third, colleges and universities should fully respect the independent initiative of students ${ }^{[1]}$. Teachers should give corresponding assistant guidance to students' mastery of vocal knowledge, so that college vocal multicultural education system can better meet the needs of students at different levels, ensuring that all students are teaching. Enjoy the most efficient vocal education.

\subsection{Eliminate the "dualistic" thinking and enhance the emphasis on local vocal culture education}

Music has its unique artistic charm and important artistic appreciation value. In the process of development, there is no distinction between high and low and noble and the vocal music culture are gradually enriched and diversified. College vocal teachers themselves need to treat them equally. Chinese vocal music education completely eliminates the "dualistic" thinking. Specifically improve from the following aspects:

- Fully enhance the emphasis of college students on traditional Chinese vocal music culture.

$\checkmark$ Add a traditional Chinese vocal music education course to the university vocal music education system.

- Help students to establish healthy vocal thinking and fully mobilize students' subjective initiative.

$\checkmark$ Reform and innovate the vocal education system in colleges and universities in a multicultural perspective.

- Adhere to the national singing art and make full use of the laws of natural commonality of national singing art $^{[4]}$. 


\subsection{Enhancing the multicultural competence of vocal music education in colleges and universities}

The multicultural reform of vocal music education in colleges and universities has become an inevitable trend in the development of music colleges, and teachers are the dominant players in vocal music education courses. Therefore, universities must strengthen the training of multicultural competence of vocal teachers. The diversified development of vocal music culture makes the overall quality of vocal music teachers in colleges and universities more demanding. Therefore, teachers only have certain musical literacy and multicultural ability to cultivate students' vocal music multicultural literacy. Therefore, colleges and universities need to realize the multicultural competence training of teachers from three aspects: First, in the teaching of vocal music education, teachers should be promoted to respect the vocal culture of different nationalities, so that students can enhance their recognition of traditional vocal culture in China. The second is to establish a platform for communication and sharing among teachers, to achieve mutual complementarity of teachers' teaching resources, and to promote the professional quality and multicultural ability of vocal teachers in colleges and universities. The third is to increase the number of vocal teacher training and outings as much as possible to ensure that teachers can update their vocal culture knowledge structure and improve their vocal culture education ability.

\section{Conclusions}

In summary, with the continuous development of the social economy and the continuous exchange of global culture, the teaching of national music in China is also constantly developing. Therefore, the development of national vocal music in China should also adapt to the status quo of multicultural development. All schools should also conduct research and analysis on the problems arising in the teaching of national vocal music, break the traditional teaching methods and teaching systems, and adjust according to the development and needs of various national cultures. The education reform of national vocal music actively seeks new teaching methods and systems, continuously innovates national vocal music education, and makes national vocal music education meet the requirements of the development of multiculturalism in China today, and promotes the all-round development of national vocal music education.

\section{References}

[1] Kumar M, Rodrigues V S. Synergetic Effect of Lean and Green on Innovation: A Resource-based perspective [J]. International Journal of Production Economics, 2018:S0925527318301622.

[2] Mejlgaard N, Christensen MV, Strand R, et al. Teaching Responsible Research and Innovation: A Phronetic Perspective [J]. Science \& Engineering Ethics, 2018(1):1-19.

[3] Zhao J, Luan D, Xi X. Research on the strategic alliance innovation system evolution mechanism: the perspective of knowledge flow [J]. Cluster Computing, 2018(4):1-19.

[4] Rice, Eric/Petering, Robin/Stringfellow, Erin/Craddock, Jaih B. Innovations in Community-Based and Interdisciplinary Research: A Network Perspective on Innovation in Social Work Science.[J]. Research on Social Work Practice, 2017, 27(2):189-193.

[5] Liu J Y, Lu L S. A study on the exhibition and performing arts pattern of rural villages based on the perspective of design aesthetics[C]// International Conference on Applied System Innovation. 2017. 